GERON, L.J.V. et al. Composição bromatológica e produção de biomassa da Urochloa brizantha cv. Marandu no período da seca na região Sudoeste de Mato Grosso. PUBVET, Londrina, V. 7, N. 17, Ed. 240, Art. 1587, Setembro, 2013.

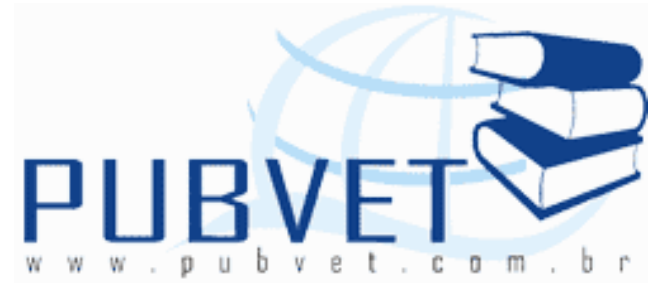

PUBVET, Publicações em Medicina Veterinária e Zootecnia.

\title{
Composição bromatológica e produção de biomassa da Urochloa brizantha cv. Marandu no período da seca na região Sudoeste de Mato
} Grosso

Luiz Juliano Valério Geron ${ }^{1}$, Alline Mariá Schumann², Alexandre Agostinho Mexia ${ }^{1}$, Raquel Joana Trautmann-Machado ${ }^{3}$, Jocilaine Garcia ${ }^{1}$, Maria Aparecida Pereira Pierangeli ${ }^{4}$, Eurico Lucas de Sousa Neto ${ }^{5}$, Renato Tonhá Alves Júnior ${ }^{6}$

1 Doutor em Zootecnia, Prof. do Departamento de Zootecnia (DZO) da Universidade do Estado de Mato Grosso (UNEMAT). e-mail: ljgeron@unemat.br

${ }^{2}$ Mestranda do Instituto de Zootecnia - IZ.

e-mail: allineschumann@yahoo.com.br;

${ }^{3}$ Mestre em Ciências Ambientais, Prof ${ }^{\mathrm{a}}$. DZO/UNEMAT;

${ }^{4}$ Doutora em Ciências do Solo, Prof ${ }^{a}$. DZO/UNEMAT;

${ }^{5}$ Doutorando em Ciências do Solo, Prof. DZO/UNEMAT;

${ }^{6}$ Zootecnista formado pela UNEMAT.

\section{Resumo}

Avaliou-se a composição bromatologica e a produção da biomassa - PBM expressa na matéria natural - MN e matéria seca - MS da Urochloa brizantha cv. Marandu no período da seca utilizada na produção de cordeiros suplementados com caroço de algodão e grão de milho moído (CAGM), durante ensaio de desempenho animal na região Sudoeste de Mato Grosso. Foram utilizados 28 
GERON, L.J.V. et al. Composição bromatológica e produção de biomassa da Urochloa brizantha cv. Marandu no período da seca na região Sudoeste de Mato Grosso. PUBVET, Londrina, V. 7, N. 17, Ed. 240, Art. 1587, Setembro, 2013.

cordeiros sem raça definida com peso corporal de aproximadamente $19 \mathrm{~kg}$ até atingirem 0 peso de abate de aproximadamente $30 \mathrm{~kg}$. Os cordeiros permaneceram durante o período diurno em um piquete de 2,5 ha de Urochloa Brizantha (capim Marandu). Foi utilizado um delineamento inteiramente casualizado para determinação da PBM em $\mathrm{kg} \mathrm{ha}^{-1}$ na MN e MS da do capim Marandu para os cinco meses de avaliação (junho, agosto, setembro outubro e novembro). Para a determinação da PBM e composição bromatologica do capim Marandu foram colhidas vinte amostras do capim ha-1 ${ }^{-1}$ as quais foram separadas para cada componente da planta (planta inteira, lamina foliar, pseudocolmos e material senescente) mês ${ }^{-1}$. Os dados das variáveis estudas (PBM) foram submetidos a análise de variância e as diferenças obtidas foram testadas utilizando o teste de Tukey a 5\% de probabilidade. Foi observado que o teor de MS do capim Marandu na planta inteira (PI) alcançou maior valor nos meses de agosto e setembro $(70,22 \%$ e $72,34 \%$, respectivamente), em relação aos demais meses estudados. A PBM de MN em $\mathrm{kg} \mathrm{ha}^{-1}$ de lamina foliar (LF) do capim Marandu foi maior $(P<0,05)$ para o mês de novembro em relação aos demais. $A$ PBM expressa na MS da PI em $\mathrm{kg} \mathrm{ha}^{-1}$ apresentou maior $(P<0,05)$ valor no mês de julho em relação aos demais meses avaliados. A quantidade de biomassa na MS da LF em $\mathrm{kg} \mathrm{ha}^{-1}$ e na percentagem da PI do capim Marandu foi maior $(\mathrm{P}<0,05)$ para o mês de agosto e novembro. A produção de biomassa na $\mathrm{MN} \mathrm{kg}$ ha ${ }^{-1}$ do capim Marandu é extremamente comprometida nos meses de agosto e setembro e a produção de biomassa na MS $\mathrm{kg} \mathrm{ha}^{-1}$ apresenta piores valores no mês de setembro e novembro. Assim, existe a necessidade do produtor suplementar os cordeiros produzidos a pasto durante os meses de agosto a novembro, devido à diminuição da PBM e qualidade da Urochloa brizantha cv. Marandu na região Sudoeste de Mato Grosso.

Palavras-chave: fibra em detergente neutro; matéria natural, matéria seca, proteína bruta 
GERON, L.J.V. et al. Composição bromatológica e produção de biomassa da Urochloa brizantha cv. Marandu no período da seca na região Sudoeste de Mato Grosso. PUBVET, Londrina, V. 7, N. 17, Ed. 240, Art. 1587, Setembro, 2013.

\section{Chemical composition and biomass production Urochloa brizantha cv. Marandu the period of drought in the southwest region of Mato Grosso}

\section{Abstract}

That was evaluated the chemical composition and biomass production - BPR expressed in natural matter - NM and dry matter - DM Urochloa brizantha cv. Marandu during the dry season used in the production of lambs supplemented with cottonseed and corn grain (CSCG) during performance test animal in the Southwest region of Mato Grosso. We used 28 mongrel lambs weighing approximately $19 \mathrm{~kg}$ to reach slaughter weight of approximately $30 \mathrm{~kg}$. The lambs were kept during the day in a paddock of 2.5 ha of Urochloa Brizantha (grass Marandu). We used a completely randomized design to determine the BPR in $\mathrm{kg}$ $\mathrm{ha}^{-1}$ NM and DM from the grass Marandu for the five month evaluation (June, August, September, October and November). To determination of the BPR and chemical composition of the grass Marandu were collected twenty samples from grass $\mathrm{ha}^{-1}$, which were separated for each component of the plant (whole plant, leaf lamina, pseudostems and dead material) month ${ }^{-1}$. The data for the variables studied (BPR) were submitted to analysis of variance and the differences were tested using the Tukey test at $5 \%$ probability. It was observed that the DM content of the grass Marandu in the whole plant (WP) reached the highest value in the months of august and september ( $70.22 \%$ and $72.34 \%$, respectively), compared to other months studied. The BPR on NM express $\mathrm{kg} \mathrm{ha}^{-1}$ of leaf lamina $(L F)$ of the grass Marandu was higher $(P<0.05)$ for the month of november compared to the others. The BPR expressed on DM in the WP in $\mathrm{kg} \mathrm{ha}^{-1}$ had greater $(P<0.05)$ value in July compared to the others evaluated. The amount of biomass in the DM of the LF in $\mathrm{kg} \mathrm{ha}^{-1}$ and the percentage of WP of the grass Marandu was higher $(P<0.05)$ for the month of august and november. The biomass production in NM $\mathrm{kg} \mathrm{ha}^{-1}$ grass Marandu is extremely committed in 
GERON, L.J.V. et al. Composição bromatológica e produção de biomassa da Urochloa brizantha cv. Marandu no período da seca na região Sudoeste de Mato Grosso. PUBVET, Londrina, V. 7, N. 17, Ed. 240, Art. 1587, Setembro, 2013.

august and september and biomass production in $\mathrm{DM} \mathrm{kg} \mathrm{ha}{ }^{-1}$ presents the worst values in september and november. Thus, there need of the supplementation to lambs produced on pasture during the months from august to november due to decreased BPR and quality Urochloa brizantha cv. Marandu in the Southwest region of Mato Grosso.

Keywords: neutral detergent fiber, natural matter, dry matter, crud protein

\section{INTRODUÇÃO}

No Brasil, até o final da década de 60, a pecuária era usada por grandes latifundiários para caracterizar a posse da terra. Historicamente, o sistema de produção predominante era extrativista, sobre pastagens nativas, sem preocupação com investimentos e adoção de tecnologia (Barbosa et al., 2008) para melhoria dos sistemas produtivos.

De acordo com Aidar et al. (2005), a maior parte da área do Cerrado está ocupada com pastagem. Neste bioma existem cerca de 75 milhões de hectares de pasto nativo, naturalmente improdutivo e de baixo valor alimentar, e outros 50 milhões de hectares de pasto cultivado, dos quais se estimam que mais de $80 \%$ apresentam algum grau de degradação, sendo este apontado como um dos maiores problemas sociais, econômicos e ambientais, vividos pela pecuária regional (Barcellos et al., 2001), além de ser considerado o maior problema relacionado com a sustentabilidade da produção animal em pastagem (Macedo, 2000).

Existe uma concepção extrativista e tradicionalista (Silva e Pereira, 1997) de que os pastos devem ser estabelecidos em áreas que apresentem sérias limitações à produção de culturas e, mesmo em tais condições, seja capaz de produzir grandes quantidades de forragens de elevado valor nutritivo e de baixo custo (Silva, 1995 e Lupinacci, 2002). O planejamento conservacionista do uso da terra utilizado no Brasil (Lepsch, 1983; Ramalho Filho e Beek, 1995) e no mundo 
GERON, L.J.V. et al. Composição bromatológica e produção de biomassa da Urochloa brizantha cv. Marandu no período da seca na região Sudoeste de Mato Grosso. PUBVET, Londrina, V. 7, N. 17, Ed. 240, Art. 1587, Setembro, 2013.

(Ramalho Filho e Pereira, 1999) recomenda que as melhores áreas sejam destinadas para as lavouras anuais, e para às pastagens sejam utilizadas aquelas áreas com maiores limitações agronômicas (fertilidade, risco a erosão etc).

O Brasil apresenta características climáticas que favorecem a exploração de forragens com elevado potencial de produção de biomassa. As áreas de pastagens do Brasil segundo dados da Food and Agriculture Organization (FAO, 2003) é de aproximadamente 180 milhões de hectares, ou seja, cerca de $20 \%$ do território nacional é ocupado por plantas forrageiras.

Segundo Costa et al. (2005), a Urochloa ssp. é o capim mais plantado no Brasil e utilizado na fase de cria, recria e engorda dos animais. O grande interesse dos pecuaristas pelo gênero Urochloa ssp., é devido a esse apresentar alta produção de biomassa e matéria seca, possuírem boa adaptabilidade, facilidade de estabelecimento, persistência e bom valor nutritivo, além de apresentarem poucos problemas de doenças e mostrarem bom crescimento durante a maior parte do ano, inclusive no período seco.

A maior área plantada com Urochloa ssp. no Brasil está na região CentroOeste, sujeita a grandes variações estacionais de temperatura e umidade. O período chuvoso desta região é caracterizado pela ocorrência de temperaturas e índices pluviométricos elevados, com altas taxas de evapotranspiração. Na época seca, apresenta fotoperíodo mais curto, baixas temperaturas noturnas e a baixa umidade; devido à menor pluviosidade, podem limitar o crescimento das gramíneas, promovendo assim acentuado comportamento estacional (Costa et al., 2005).

A água é isoladamente o fator que mais limita a produção de forragem. A radiação solar, como fonte primária de energia indispensável à vida vegetal, regula a fotossíntese e todo o desenvolvimento da planta, enquanto a temperatura exerce papel marcante na fase bioquímica de carboxilação e regula o dióxido de carbono da fotossíntese (Costa et al., 2008). 
GERON, L.J.V. et al. Composição bromatológica e produção de biomassa da Urochloa brizantha cv. Marandu no período da seca na região Sudoeste de Mato Grosso. PUBVET, Londrina, V. 7, N. 17, Ed. 240, Art. 1587, Setembro, 2013.

As maiores mudanças que ocorrem na composição química e bromatológica das plantas forrageiras são aquelas decorrentes da sua maturidade (Balsolobre et al., 2001). Para Euclides et al. (1995), à medida que a planta forrageira amadurece, a quantidade de nutrientes potencialmente digestíveis (carboidratos solúveis, proteínas etc.), tende a decrescer, enquanto os teores de lignina, celulose, hemicelulose e outras frações indigestíveis (cutina, sílica etc.) aumentam acarretando a diminuição da digestibilidade da forragem.

A Urochloa brizantha cv. Marandu (capim Marandu) tem sido muito utilizada em função das suas características, como tolerância à baixa fertilidade do solo, resistência à cigarrinha das pastagens e elevada produtividade quando devidamente adubada e manejada (Andrade, 2003).

Existem problemas relacionados à grande área ocupada pelo capim Marandu com cerca de 60 milhões de hectares, pois o cultivo desta monocultura em várias regiões do país leva ao surgimento de casos de morte desta pastagem no norte do país, reforçando a necessidade de avaliação, utilização e geração de pesquisa sobre esta e outras cultivares da Urochloa ssp (Costa et al., 2005).

O bom desempenho da Urochloa brizantha deve-se à sua adequação em todos os tipos de solo, porém apresenta o hábito de crescimento prostrado e agressivo, o que não tem permitido a sua associação com leguminosas, com isso dificultando a diversificação e a complementação alimentar dos animais no campo. O manejo inadequado das pastagens de Urochloa ssp. na região do Cerrado pode ocasionar diminuição da cobertura superficial e, com isso, empobrecimento do solo devido ao processo de erosão e, conseqüentemente, queda de produção da biomassa (Goedert, 1985).

Para a realização de um manejo da pastagem adequado é necessário ajustar oferta de forragem para otimizar seu uso, o que possibilita a máxima colheita de material verde (biomassa) com o mínimo de perda por senescência gerando um ponto de equilíbrio entre os componentes do ecossistema e sua sustentabilidade 
GERON, L.J.V. et al. Composição bromatológica e produção de biomassa da Urochloa brizantha cv. Marandu no período da seca na região Sudoeste de Mato Grosso. PUBVET, Londrina, V. 7, N. 17, Ed. 240, Art. 1587, Setembro, 2013.

(Pernelli, 2003). Na exploração racional é relevante que a pastagem apresente persistência e alta produção de biomassa com alto valor nutritivo e que o animal possa expressar o máximo de seu potencial genético, para otimizar o produção vegetal e animal no ambiente.

Segundo Van Soest (1982), os derivados (proteínas e carboidratos totais) das plantas vêm da energia solar e da fixação de carbono no interior da estrutura celular, e a distribuição deste carbono e energia, dentro da planta, é afetada pela seletividade dos fatores ambientais. O crescimento do pasto é dado pela capacidade da planta em converter a energia luminosa em biomassa vegetal. No entanto, esses derivados das plantas variam em função da idade, da parte da planta, da época do ano e da fertilidade do solo (Werner, 1993 e Werner, 1994). O baixo valor nutritivo em parte decorrente da ampla variação da composição química das forrageiras tropicais é, freqüentemente, mencionado na literatura. Este valor nutritivo está associado aos reduzidos teores de proteína bruta e minerais, ao alto conteúdo de fibra e à baixa digestibilidade da matéria seca (Euclides, 1995 e Schumann et al., 2009).

Desta maneira, objetivou-se avaliar a produção da biomassa - PBM expressa na matéria natural (MN) e matéria seca (MS) além da composição bromatológica (teor de matéria seca - MS, matéria orgânica - MO, proteína bruta - PB, extrato etéreo - $\mathrm{EE}$, fibra em detergente neutro - FDN, fibra em detergente ácido - FDA e matéria mineral - MM) da Urochloa brizantha cv. Marandu no período da seca (junho, agosto, setembro, outubro e novembro), durante ensaio de desempenho animal de cordeiros suplementados com níveis crescentes de concentrado na região Sudoeste de Mato Grosso.

\section{MATERIAL E MÉTODOS}

O estudo foi conduzido na fazenda "Pau D'Alho" localizada no município de Pontes e Lacerda-MT e no Laboratório de Análise de Alimentos e Nutrição Animal 
GERON, L.J.V. et al. Composição bromatológica e produção de biomassa da Urochloa brizantha cv. Marandu no período da seca na região Sudoeste de Mato Grosso. PUBVET, Londrina, V. 7, N. 17, Ed. 240, Art. 1587, Setembro, 2013.

(LAANA) pertencente ao Departamento de Zootecnia do Campus Universitário de Pontes e Lacerda da Universidade do Estado de Mato Grosso (UNEMAT).

Foi realizado um ensaio de desempenho animal com 28 cordeiros machos desmamados sem raça definida com peso corporal (PC) médio de $19 \pm 0,5 \mathrm{~kg}$, distribuídos em um piquete de Urochloa brizantha cv. Marandu (capim Marandu) com 2,5 hectares, até atingirem o PC de abate de $30 \mathrm{~kg}$, alimentados com uma suplementação concentrada de $0,0 \% ; 0,5 \% ; 1,0 \%$ e $1,5 \%$ do PC constituída de caroço de algodão mais grão de milho moído (CAGM). Foi adotado o método de lotação contínua, com carga fixa no piquete (Pruhmann et al., 2004). Os cordeiros foram pesados a cada 15 dias para o ajuste do fornecimento da suplementação concentrada, os animais permaneceram na pastagem até atingirem o PC de abate de aproximadamente $30 \mathrm{~kg}$.

Foi realizada a coleta de solo na área de avaliação para obtenção da classificação e análise química na condição do desenvolvimento da pesquisa. A análise de solo foi realizada no Laboratório de Análise de Solos (LAS) do Campus Universitário de Pontes e Lacerda (UNEMAT).

O solo foi classificado como Argissolo Vermelho (Embrapa, 2006) e analisado para avaliação da fertilidade (Tabela 1 ) seguindo metodologias preconizadas em Embrapa (1997). O piquete com capim Marandu não recebeu adubação seguindo a rotina usual da fazenda Pau D'Alho.

Para avaliação da produção da biomassa expressa em matéria natural - MN e na matéria seca - MS por hectare (ha) e composição bromatológica da forragem (capim Marandu), foram realizadas amostragens casualizadas no mesmo período de determinação do desempenho animal (julho, agosto, setembro, outubro e novembro) de cordeiros suplementados a pasto.

A disponibilidade de biomassa da forragem foi estimada a cada 30 dias utilizando-se o método de dupla amostragem (Wilm et al., 1944). Foram colhidas vinte amostras ao acaso no piquete a cada 30 dias, cortadas $5 \mathrm{~cm}$ do nível do 
GERON, L.J.V. et al. Composição bromatológica e produção de biomassa da Urochloa brizantha cv. Marandu no período da seca na região Sudoeste de Mato Grosso. PUBVET, Londrina, V. 7, N. 17, Ed. 240, Art. 1587, Setembro, 2013.

solo, pesadas e secas em estufa de ventilação forçada a $55^{\circ} \mathrm{C}$. Foi considerado os valores das amostras cortadas (20) e as estimadas visualmente (30), para efetuar o cálculo da produção de biomassa na MN e na MS, em $\mathrm{kg} \mathrm{ha}^{-1} \mathrm{mês}^{-1}$, utilizando-se a equação proposta por Gardner (1986).

Tabela 1. Atributos da fertilidade do solo da fazenda Pau D'Alho, município de Pontes e Lacerda, região Sudoeste de Mato Grosso - MT.

\begin{tabular}{|c|c|c|}
\hline Atributo & Resultados & Unidade de medida \\
\hline \multicolumn{3}{|c|}{ Macronutrientes } \\
\hline $\mathrm{pH}_{\mathrm{H} 2 \mathrm{O}}$ & 5,1 & - \\
\hline $\mathrm{pHCaCl}_{2}$ & - & - \\
\hline $\mathrm{MO}$ & 1,5 & dag $\mathrm{kg}^{-1}$ \\
\hline$P$ & 1,0 & $\mathrm{mg} \mathrm{dm}^{-3}$ \\
\hline$S$ & - & $\mathrm{mg} \mathrm{dm} \mathrm{dm}^{-3}$ \\
\hline K & 64,1 & $\mathrm{mg} \mathrm{dm} \mathrm{dm}^{-3}$ \\
\hline $\mathrm{K}^{+}$ & 0,2 & $\mathrm{cmol}_{\mathrm{c}} \mathrm{dm}^{-3}$ \\
\hline $\mathrm{Ca}^{2+}$ & 0,8 & $\mathrm{cmol}_{\mathrm{c}} \mathrm{dm}^{-3}$ \\
\hline $\mathrm{Mg}^{2+}$ & 0,6 & $\mathrm{cmol}_{\mathrm{c}} \mathrm{dm}-3$ \\
\hline $\mathrm{Na}^{+}$ & - & $\mathrm{cmol}_{\mathrm{c}} \mathrm{dm}^{-3}$ \\
\hline $\mathrm{Al}^{3+}$ & 0,6 & $\mathrm{cmol}_{\mathrm{c}} \mathrm{dm}^{-3}$ \\
\hline $\mathrm{H}+\mathrm{Al}$ & 5,7 & $\mathrm{cmol}_{\mathrm{c}} \mathrm{dm}^{-3}$ \\
\hline CTC efetiva & 2,2 & $\mathrm{cmol}_{\mathrm{c}} \mathrm{dm}^{-3}$ \\
\hline $\mathrm{CTC}_{\mathrm{pH} 7,0}$ & 7,3 & $\mathrm{cmol}_{\mathrm{c}} \mathrm{dm}^{-3}$ \\
\hline V & 21,4 & $\%$ \\
\hline $\mathrm{m}$ & 27,8 & $\%$ \\
\hline \multicolumn{3}{|c|}{ Granulometria } \\
\hline Argila & 293,7 & $\mathrm{~g} \mathrm{~kg}^{-1}$ \\
\hline Silte & 115,1 & $\mathrm{~g} \mathrm{~kg}^{-1}$ \\
\hline Areia & 591,2 & $\mathrm{~g} \mathrm{~kg}^{-1}$ \\
\hline \multicolumn{3}{|c|}{ Saturacão do complexo de troca } \\
\hline $\mathrm{K}$ & 7,3 & $\%$ \\
\hline $\mathrm{Ca}$ & 36,4 & $\%$ \\
\hline $\mathrm{Mg}$ & 27,3 & $\%$ \\
\hline $\mathrm{Na}$ & - & $\%$ \\
\hline
\end{tabular}

O número elevado de amostragens (50) de forragem (capim Marandu) cortada e estimada visualmente ha ${ }^{-1}$ mês $^{-1}$ foi realizada com o intuito de se evitar uma estimativa tendenciosa das características da população forrageira e da produção de biomassa além de estimar satisfatoriamente o erro (Difante, 2003). 
GERON, L.J.V. et al. Composição bromatológica e produção de biomassa da Urochloa brizantha cv. Marandu no período da seca na região Sudoeste de Mato Grosso. PUBVET, Londrina, V. 7, N. 17, Ed. 240, Art. 1587, Setembro, 2013.

Após fracionar a forragem coletada na dupla amostragem em subamostras, separou-se os componentes da planta (lamina foliar, pseudocolmos e material senescente). Cada fração foi posteriormente, seca em estufa de ventilação forçada com temperatura média de $55^{\circ} \mathrm{C}$ por 72 horas, pesada e moída a $1 \mathrm{~mm}$, em moinho de faca (tipo Willey), e conservadas em recipientes hermeticamente fechados para posteriores análises químicas.

Para a determinação da composição química e bromatológica do capim Marandu as vinte subamostras de cada mês de cada componente da planta (planta inteira, lamina folhiar, pseudocolmos e material senescente) formou uma amostra total por componente morfológico.

As amostras de planta inteira, lâminas foliares, pseudocolmos e material senescente do capim Marandu foram avaliadas quanto aos teores de matéria seca (MS), matéria orgânica (MO), matéria mineral (MM), proteína bruta (PB), extrato etéreo ( $E E)$, fibra em detergente neutro (FDN) e fibra em detergente ácido (FDA).

A determinação do teor de MS definitiva do capim Marandu para os diferentes meses avaliados foi realizada em estufa a $105^{\circ} \mathrm{C}$, o teor de nitrogênio foi obtido pelo método semimicro-Kjeldahl, usando-se 6,25 como fator de conversão para $\mathrm{PB}$, o teor de matéria mineral $(\mathrm{MM})$ foi realizada pelo método por incineração em mufla a $600^{\circ} \mathrm{C}$ e por diferença foi obtido o teor de matéria orgânica (MO) e o teor de extrato etéreo (EE) foi obtido pela extração por lavagem com éter de petróleo, segundo metodologia descrita por Silva e Queiroz (2002).

A determinação do teor de FDN e de FDA do capim Marandu foi realizada de acordo com Van Soest et al. (1991).

Foi utilizado um delineamento inteiramente casualizado para determinação da produção por hectare da biomassa expressa na matéria natural e na matéria seca da pastagem (capim Marandu) para os diferentes meses estudados no período da seca. 
GERON, L.J.V. et al. Composição bromatológica e produção de biomassa da Urochloa brizantha cv. Marandu no período da seca na região Sudoeste de Mato Grosso. PUBVET, Londrina, V. 7, N. 17, Ed. 240, Art. 1587, Setembro, 2013.

Os dados obtidos para a produção de matéria natural e matéria seca por área foi submetida a ANOVA utilizando o programa "Sistema de Análise Estatística e Genética - SAEG" (UFV, 1997), e as diferenças obtidas foram testadas utilizando o teste de Tukey a $5 \%$ de probabilidade.

Para o ensaio de desempenho animal (ganho médio diário - GMD) dos cordeiros suplementados a pasto foi considerado os diferentes níveis de suplementação concentrada durante o período de avaliação (cinco meses) e as diferenças obtidas foram submetidas a análise de regressão considerando $5 \%$ de significância.

Os dados de composição bromatológica da Urochloa brizantha (capim Marandu), não foram analisados estatisticamente devido à formação de amostras totais para as diferentes proporções da planta, para os diferentes meses de avaliação, não havendo número adequado de repetições em função dos meses avaliados.

\section{RESULTADOS E DISCUSSÃO}

Foi observado que o solo da área onde o experimento foi conduzido (região Sudoeste de Mato Grosso) é de baixa fertilidade $(\mathrm{V}<50 \%)$, além de apresentar acidez média (Souza e Lobato, 2004) e baixos teores de fosforo (P) (Tabela 1).

Segundo Cantarutti et al. (1999), o capim Marandu é uma variedade de forrageira que exige que o solo tenha no mínimo $45 \%$ de saturação por bases (V) e $1,5 \mathrm{cmol}_{\mathrm{c}} \mathrm{dm}^{-3}$ de $\mathrm{Ca}+\mathrm{Mg}$.

Os valores da composição bromatológica da Urochloa brizantha cv. Marandu para a planta inteira, lamina foliar, pseudocolmo e material senescente dos diferentes meses avaliados na região Sudoeste de Mato Grosso podem ser observados na Tabela 2. 
GERON, L.J.V. et al. Composição bromatológica e produção de biomassa da Urochloa brizantha cv. Marandu no período da seca na região Sudoeste de Mato Grosso. PUBVET, Londrina, V. 7, N. 17, Ed. 240, Art. 1587, Setembro, 2013.

Tabela 2. Composição bromatológica da Urochloa brizantha cv. Marandu no período da seca na região Sudoeste do Estado de Mato Grosso expressa em \%MS.

\begin{tabular}{|c|c|c|c|c|c|}
\hline \multirow{2}{*}{ Variável } & \multicolumn{5}{|c|}{ Período de produção de biomassa da Urochloa brizantha cv. Marandu } \\
\hline & Julho & Agosto & Setembro & Outubro & Novembro \\
\hline \multicolumn{6}{|c|}{ Planta Inteira } \\
\hline MS \% & 64,73 & 70,22 & 72,34 & 66,29 & 32,98 \\
\hline MO \% & 90,96 & 90,57 & 91,36 & 92,11 & 90,93 \\
\hline PB \% & 3,89 & 3,59 & 3,04 & 6,20 & 5,90 \\
\hline EE \% & 0,78 & 0,61 & 0,96 & 1,37 & 1,21 \\
\hline FDN $\%$ & 72,07 & 71,25 & 72,89 & 72,76 & 72,70 \\
\hline FDA \% & 44,64 & 42,65 & 46,63 & 44,61 & 41,51 \\
\hline MM \% & 9,04 & 9,43 & 8,64 & 7,89 & 9,07 \\
\hline \multicolumn{6}{|c|}{ Lamina Foliar } \\
\hline MS \% & 44,52 & 53,06 & 46,36 & 24,62 & 30,18 \\
\hline MO \% & 92,30 & 93,33 & 92,71 & 90,56 & 91,91 \\
\hline PB \% & 5,37 & 5,25 & 4,11 & 6,01 & 6,37 \\
\hline EE \% & 0,62 & 0,59 & 0,41 & 0,71 & 1,94 \\
\hline FDN \% & 66,94 & 65,91 & 65,17 & 65,68 & 64,27 \\
\hline FDA \% & 44,07 & 55,33 & 49,90 & 35,55 & 36,41 \\
\hline MM \% & 7,70 & 6,67 & 7,29 & 9,44 & 8,09 \\
\hline \multicolumn{6}{|c|}{ Pseudocolmo } \\
\hline MS \% & 58,39 & 62,60 & 51,94 & 39,26 & 44,66 \\
\hline MO \% & 94,58 & 96,04 & 96,32 & 96,15 & 95,69 \\
\hline PB \% & 2,44 & 2,61 & 2,51 & 3,22 & 3,42 \\
\hline EE \% & 0,66 & 0,87 & 0,55 & 0,70 & 0,71 \\
\hline FDN \% & 74,14 & 75,40 & 77,31 & 75,99 & 73,48 \\
\hline FDA \% & 47,01 & 45,94 & 49,32 & 45,47 & 45,32 \\
\hline MM \% & 5,42 & 3,96 & 3,68 & 3,85 & 4,31 \\
\hline \multicolumn{6}{|c|}{ Material senescente } \\
\hline MS \% & 92,00 & 86,06 & 85,17 & 69,38 & 77,05 \\
\hline MO \% & 90,55 & 91,54 & 92,14 & 90,93 & 91,00 \\
\hline PB \% & 2,22 & 2,58 & 2,28 & 2,67 & 2,75 \\
\hline EE \% & 0,57 & 1,87 & 1,83 & 1,93 & 0,92 \\
\hline FDN $\%$ & 75,18 & 77,87 & 78,22 & 75,95 & 72,54 \\
\hline FDA \% & 57,74 & 51,57 & 49,41 & 51,47 & 51,51 \\
\hline MM \% & 9,45 & 8,41 & 7,86 & 9,07 & 9,00 \\
\hline
\end{tabular}

MS: matéria seca; MO Matéria orgânica; PB: Proteína bruta: EE: extrato etéreo; FDN: Fibra em detergente neutro; FDA: Fibra em detergente neutro e MM: matéria mineral.

Foi observado que o teor de MS do capim Marandu na planta inteira alcançou maior valor nos meses de agosto e setembro (70,22\% e 72,34\%, 
GERON, L.J.V. et al. Composição bromatológica e produção de biomassa da Urochloa brizantha cv. Marandu no período da seca na região Sudoeste de Mato Grosso. PUBVET, Londrina, V. 7, N. 17, Ed. 240, Art. 1587, Setembro, 2013.

respectivamente), em relação aos demais meses estudados. Essa variação no teor de MS pode ter ocorrido devido à baixa precipitação pluviométrica (Tabela 3) ocorrido neste período na fazenda Pau D'Alho - MT, o que acarretou em maior concentração de biomassa seca em relação ao conteúdo de água total na planta (matéria natural da forragem).

O mês de Julho apresentou o menor índice pluviométrico de todo o período (Tabela 3), porém o teor de MS nesse mês não foi o mais baixo quando comparado aos outros meses avaliado. Isso pode ser explicado devido ao fato de que nos meses anteriores a Julho ocorreu alta precipitação (período das águas), o que pode ter contribuído para o aumento no teor de MS no decorrer do período, até a umidade do solo alcançar níveis baixos não atendendo as exigências hídricas da Urochloa brizantha cv. Marandu.

Tabela 3. Precipitação pluviométrica na fazenda Pau D'Alho, localizada na região do Sudoeste do Mato Grosso para os meses experimentais.

\begin{tabular}{lccccc}
\hline \multirow{2}{*}{ Variável } & \multicolumn{5}{c}{ Período de avaliação experimental (Meses) } \\
\cline { 2 - 6 } & Julho & Agosto & Setembro & Outubro & Novembro \\
\hline Milímetros & 0 & 20 & 15 & 18 & 90 \\
\hline
\end{tabular}

Fonte: Fazenda Lagoa do Guaporé e Pau D'Alho no ano de 2008.

O capim Marandu apresentou um teor de PB expresso na MS para a planta inteira de 3,59\% e 3,04\% nos meses de agosto e setembro, respectivamente, entretanto nos meses de outubro e novembro o teor de PB foi de 6,20\% e 5,90\%, respectivamente (Tabela 2). Esta variação no teor de PB entre os meses de agosto e setembro em relação a outubro e novembro pode ser devido à quantidade de chuvas e também ao aumento do período luminoso a partir dos meses de outubro, o que pode ter acelerado o metabolismo da planta aumentando o conteúdo celular e conseqüentemente o teor de PB (Costa et al., 2008).

Os valores de fibra em detergente neutro (FDN) e fibra em detergente ácido 
GERON, L.J.V. et al. Composição bromatológica e produção de biomassa da Urochloa brizantha cv. Marandu no período da seca na região Sudoeste de Mato Grosso. PUBVET, Londrina, V. 7, N. 17, Ed. 240, Art. 1587, Setembro, 2013.

(FDA) para a planta inteira do capim Marandu durante os meses avaliados apresentaram uma baixa variação, com um valor médio de $72,33 \%$ e de $44,01 \%$, respectivamente. Provavelmente essa baixa variação nos teores de FDN e FDA da planta inteira, pode ter ocorrido devido ao material senescente, que se acumulou durante os três primeiros meses (julho, agosto e setembro), o que contribuiu desta maneira, para essa constância nos resultados obtidos para os carboidratos estruturais (FDN e FDA).

Da mesma forma estudo realizado por Andrade (2003), para avaliar os teores de FDN e FDA na pastagem formada por capim Marandu, observou aumento no teor destes apenas nos períodos de dezembro a março comparado as demais épocas do ano, uma vez que foram verificadas maiores acúmulos de forragem neste período. Os dados obtidos por Andrade (2003) corroboram com o observado no presente estudo, no qual o teor de FDN e FDA apresentaram pouca variação no decorrer do período avaliado (julho a novembro).

Estudo realizado por Machado et al. (1998), para avaliar a altura de corte de Panicum maximus no período do verão e inverno, mostraram valores para o teor de FDN inferiores no período de inverno comparativamente com o verão. Estes autores justificaram que esta diferença pode ser gerada pela intensidade da atividade metabólica da planta durante o verão, o que levou a um aumento de seus constituintes de parede celular para que não ocorra rompimento das células devido à alta absorção de água. Além disso, segundo os mesmos autores, esse metabolismo ocorreu de forma mais amena no período do inverno, o que propiciou menor variação no teor da FDN e FDA neste período do ano.

Os teores médios de MS para os três primeiros meses avaliados para lâmina foliar, pseudocolmo e material senescente do capim Marandu produzido na região Sudoeste de Mato Grosso foram de 47,98\%; $57,64 \%$ e 87,74\%, respectivamente, superiores aos valores médios observados para dois últimos meses avaliados (outubro e novembro) com valor de $27,40 \% ; 41,96 \%$ e $73,22 \%$, para lamina 
GERON, L.J.V. et al. Composição bromatológica e produção de biomassa da Urochloa brizantha cv. Marandu no período da seca na região Sudoeste de Mato Grosso. PUBVET, Londrina, V. 7, N. 17, Ed. 240, Art. 1587, Setembro, 2013.

foliar, pseudocolmo e material senescente, respectivamente (Tabela 2). Essa variação no teor de MS das diferentes partes do capim Marandu pode ter ocorrido devido a quantidade de chuvas ocorrida no período avaliado na região Sudoeste de Mato Grosso conforme a Tabela 3. Deste modo, a expansão foliar pode ser reduzida mesmo em condições leves de estresse hídrico, pois a turgência é mantida por regulação osmótica o que gera um custo metabólico, o qual é prioridade em relação ao crescimento da planta (Taiz e Zaiger, 2004).

O teor médio de PB expresso na MS da lamina foliar para os meses de julho, agosto e setembro do capim Marandu foi de 4,91\%. Para os meses de outubro e novembro o valor médio de PB para a lâmina foliar foi de 6,19\%. Pode ser observado na Tabela 2 que durante os cinco meses avaliados o teor de PB da lamina foliar apresentou teor abaixo do recomendado pela literatura para o funcionamento normal do rúmen de $7 \%$ de PB. A baixa fertilidade do solo (Tabela 1) pode ter contribuído para esse fato, haja vista que uma planta mal nutrida não consegue energia suficiente para a síntese de várias moléculas ou compostos. Desta maneira, o pecuarista deverá utilizar a suplementação concentrada (protéica) para que a eficiência de produção de cordeiros não seja prejudicada pela limitação de PB na pastagem no período de julho a novembro na região Sudoeste de Mato Grosso em pastagens não adubadas.

A concentração de EE expresso na MS da lamina foliar do capim Marandu apresentou menor valor no mês de setembro com valor de $0,41 \%$ enquanto o maior teor foi observado no mês de novembro com um valor de 1,94\%. O teor de EE nas pastagens normalmente apresenta valores abaixo de $3 \%$ conforme valores observados na literatura (Lupinacci, 2002 e Mesquita, 2008).

A produção de biomassa (PBM) expressa na matéria natural (MN) e na matéria seca (MS) em $\mathrm{kg} \mathrm{ha}^{-1}$ da Urochloa brizantha $\mathrm{cv}$. Marandu produzida na região Sudoeste de Mato Grosso para a planta inteira, lamina foliar, pseudocolmo e material senescente está apresentada na Tabela 4. 
GERON, L.J.V. et al. Composição bromatológica e produção de biomassa da Urochloa brizantha cv. Marandu no período da seca na região Sudoeste de Mato Grosso. PUBVET, Londrina, V. 7, N. 17, Ed. 240, Art. 1587, Setembro, 2013.

Tabela 4. Produção de biomassa da Urochloa brizantha cv. Marandu expressa na matéria natural (MN) e na mátria seca (MS) por hectare e em percentagem de MN e MS das diferentes partes morfológicas em relação a planta inteira (PI) nos diferentes meses de avaliação na região Sudoeste do Estado de Mato Grosso.

\begin{tabular}{|c|c|c|c|c|c|c|}
\hline \multirow[t]{2}{*}{ Variável } & \multicolumn{5}{|c|}{$\begin{array}{l}\text { Período de produção de biomassa da Urochloa brizantha cv. } \\
\text { Marandu }\end{array}$} & \multirow[t]{2}{*}{$\% \mathrm{CV}$} \\
\hline & Julho & Agosto & Setembro & Outubro & Novembro & \\
\hline \multicolumn{7}{|c|}{ Produção de matéria natural (MN) $\mathrm{kg} \mathrm{ha}^{-1}$} \\
\hline MN PI kg/ha & $5.523^{a}$ & $3.582^{\mathrm{bc}}$ & $2.431^{\mathrm{c}}$ & $4.135^{b}$ & $5.551^{a}$ & 45,29 \\
\hline MN LF kg/ha & $1.909^{\mathrm{bc}}$ & $1.929^{\mathrm{b}}$ & $1.166^{\mathrm{bc}}$ & $2.536^{\mathrm{b}}$ & $4.097^{a}$ & 25,50 \\
\hline MN PC kg/ha & $1.407^{\mathrm{a}}$ & $685^{\mathrm{b}}$ & $450^{\mathrm{b}}$ & $370^{\mathrm{b}}$ & $275^{\mathrm{b}}$ & 59,55 \\
\hline MN SE kg/ha & $1.635^{\mathrm{a}}$ & $1.155^{\mathrm{ab}}$ & $862^{b}$ & $1.215^{\mathrm{ab}}$ & $1.284^{\mathrm{ab}}$ & 37,98 \\
\hline \multicolumn{7}{|c|}{ \% MN das diferentes partes da forragem em relação a $P I$} \\
\hline$\% M N$ da LF na PI & 34,56 & 53,85 & 47,96 & 61,33 & 78,81 & - \\
\hline$\% M N$ do PC na PI & 25,48 & 19,12 & 18,51 & 8,95 & 4,95 & - \\
\hline$\% M N$ do SE na PI & 29,60 & 32,24 & 35,46 & 29,38 & 23,13 & - \\
\hline \multicolumn{7}{|c|}{ Produção de matéria seca (MS) $k g ~ h a^{-1}$} \\
\hline MS PI kg/ha & $3575^{a}$ & $2.515^{\mathrm{bc}}$ & $1.759^{c}$ & $2.471^{\mathrm{b}}$ & $1.831^{\mathrm{c}}$ & 47,78 \\
\hline MS LF kg/ha & $850^{\mathrm{bc}}$ & $1.023^{\mathrm{ab}}$ & $541^{\mathrm{d}}$ & $624^{\text {cd }}$ & $1.237^{\mathrm{a}}$ & 25,18 \\
\hline MS PC kg/ha & $822^{a}$ & $429^{b}$ & $234^{\mathrm{bc}}$ & $145^{\mathrm{c}}$ & $123^{\mathrm{c}}$ & 60,65 \\
\hline MS SE kg/ha & $1.504^{a}$ & $994^{\mathrm{ab}}$ & $734^{b}$ & $843^{b}$ & $989^{\mathrm{ab}}$ & 40,29 \\
\hline \multicolumn{7}{|c|}{ \% MS das diferentes partes da forragem em relação a $P I$} \\
\hline$\%$ MS da LF na PI & 23,78 & 40,68 & 30,76 & 25,25 & 67,56 & - \\
\hline$\% M S$ do PC na PI & 22,99 & 17,06 & 13,30 & 5,87 & 6,72 & - \\
\hline \%MS do SE na PI & 42,07 & 39,52 & 41,73 & 34,12 & 54,01 & - \\
\hline
\end{tabular}

Letras minúsculas diferente entre si nas linhas. \%CV: coeficiente de variação, teste de Tukey $(P<0,05)$. PI: planta inteira; LF: folhas; PC: colmo e SE: material senescente. Quilograma por hectare ( $\mathrm{kg} / \mathrm{ha})$.

A maior PBM $(P<0,05)$ em $\mathrm{kg} \mathrm{MN} \mathrm{ha}^{-1}$ para a planta inteira (PI) do capim Marandu foi obtida nos meses de julho e novembro em relação aos demais meses estudados. Este efeito pode estar relacionado a quantidade de chuva nestes meses e também a utilização continua do piquete após o mês de julho o que pode ter afetado a disponibilidade da MN total da área. Outro fator que pode ter contribuído para a maior $(P<0,05)$ PBM na $M N$ no mês de julho pode ter sido a precipitação ocorrida nos meses anteriores, o que favoreceu o desenvolvimento 
GERON, L.J.V. et al. Composição bromatológica e produção de biomassa da Urochloa brizantha cv. Marandu no período da seca na região Sudoeste de Mato Grosso. PUBVET, Londrina, V. 7, N. 17, Ed. 240, Art. 1587, Setembro, 2013.

da pastagem no mês de julho.

A PBM em $\mathrm{kg} \mathrm{MN} \mathrm{ha}{ }^{-1}$ de lamina foliar (LF) da Urochloa brizantha cv. Marandu foi maior $(P<0,05)$ para o mês de novembro em relação aos demais. Este efeito era esperado uma vez que no mês de novembro há um aumento na densidade pluviométrica além do aumento no fotoperíodo, conseqüentemente acarretando um aumento na síntese celular (conteúdo celular) o que leva a maior produção de LF (Hodgson, 1990).

De acordo com revisão realizada por Buxton e Fales (1994), fotoperíodos longos geralmente resultam em maiores produções de forragem (principalmente de folhas) devido ao aumento das taxas fotossintéticas o que leva a um aumento no acúmulo de conteúdo celular e uma diluição da parede celular. Outro fato que pode ter contribuído para esse fato é a ocorrências das primeiras chuvas nesse mês, o que proporciona uma intensa atividade microbiológica, após um período de menor atividade em função da escassez de água, acelerando a decomposição da matéria orgânica do solo e, conseqüentemente, aumentando a entrada de $\mathrm{N}$ no sistema (Cantarella, 2007). Tal fato estimula a emissão e crescimento foliar, haja vista que esse elemento é associado ao crescimento vegetativo das plantas (Souza e Lobato, 2004).

O capim Marandu apresentou uma maior $(P<0,05)$ PBM de MN do colmo (CO) em $\mathrm{kg} \mathrm{ha}^{-1}$ no mês de julho em relação aos demais meses avaliados. Este efeito pode ser devido à maior produção de $\mathrm{MN}\left(\mathrm{kg} \mathrm{ha}^{-1}\right)$ da planta inteira, ou seja, acumulo de pastagem, o que pode ter acarretado em maior produção de biomassa de $\mathrm{MN}$ em $\mathrm{kg} \mathrm{ha}^{-1}$ de colmo.

No mês de setembro foi observado a menor $(P<0,05)$ PBM em $\mathrm{kg} \mathrm{MN} \mathrm{ha}^{-1}$ para o material senescente (SE) do capim Marandu em relação aos demais meses avaliados. Este efeito pode estar correlacionado com a menor produção de $\mathrm{MN}$ $\left(\mathrm{kg} \mathrm{ha}^{-1}\right)$ da PI neste período, o que pode ter afetado de maneira proporcional a produção de SE da Urochloa brizantha cv. Marandu. Estudo realizado por 
GERON, L.J.V. et al. Composição bromatológica e produção de biomassa da Urochloa brizantha cv. Marandu no período da seca na região Sudoeste de Mato Grosso. PUBVET, Londrina, V. 7, N. 17, Ed. 240, Art. 1587, Setembro, 2013.

Nabinger (1997), sobre princípios de exploração intensiva de pastagens, indicou que a duração da vida das folhas e, por conseqüência, a senescência foliar, são influenciadas pela temperatura, da mesma forma que o surgimento das folhas. Dessa forma, quando um perfilho atinge seu número máximo de folhas vivas, passa haver um equilíbrio entre a taxa de surgimento de folhas e senescência das folhas mais velhas. Assim as altas temperaturas e a baixa densidade pluviométrica no mês de setembro podem ter afetado a percentagem de SE do capim Marandu neste mês em relação aos demais meses avaliados conforme observado na Tabela 3.

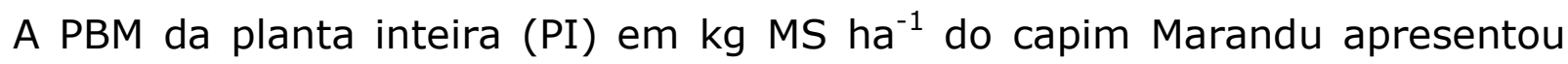
maior $(P<0,05)$ valor no mês de julho em relação aos demais meses avaliados. Esse efeito possivelmente pode ter sido influenciado pelo acumulo de água existente no subsolo devido a precipitação pluviométrica ocorrida nos meses anteriores.

A quantidade de biomassa na MS da lamina foliar em $\mathrm{kg} \mathrm{ha}^{-1}$ e na \% da PI para a Urochloa brizantha cv. Marandu foi maior $(P<0,05)$ para o mês de agosto e novembro. Provavelmente a influencia das variáveis ambientais como luz e temperatura e disponibilidade de nutrientes na produção da forrageira (Pedreira et al., 1998 e Tonato, 2003) possam ter interferido nos processos de crescimento e senescência dos tecidos o que pode ter alterado a velocidade das reações, a taxa de aparecimento de folhas, perfilhamento e conseqüentemente a produção de biomassa expressa na MS total.

A PBM de colmo em $\mathrm{kg} \mathrm{MS} \mathrm{ha}^{-1}$ e \% do PI do capim Marandu foi menor $(P<0,05)$ nos meses de setembro, outubro e novembro em relação aos demais meses. Este efeito era esperado uma vez que nos meses de outubro e novembro a pastagem começou apresentar rebrota devido a quantidades de chuvas e aumento na duração dos dias, os quais auxiliam no perfilhamento, e 
GERON, L.J.V. et al. Composição bromatológica e produção de biomassa da Urochloa brizantha cv. Marandu no período da seca na região Sudoeste de Mato Grosso. PUBVET, Londrina, V. 7, N. 17, Ed. 240, Art. 1587, Setembro, 2013.

consequentemente ocasionam aumento na quantidade e proporção de folhas em relação ao colmo.

Os maiores valores $(\mathrm{P}<0,05)$ para a PBM do material senescente $(\mathrm{SE})$ em $\mathrm{kg}$ MS ha-1 do capim Marandu foi observado para os meses de julho, agosto e novembro. Este efeito pode ter sido influenciado pela quantidade de MS total produzida por ha e a proporção de SE em relação a PI nos meses de julho, agosto e novembro.

Para o ensaio de desempenho animal (ganho de peso) foi observado um efeito quadrático $(\mathrm{P}<0,05)$ para os cordeiros recebendo diferentes níveis de $0,0 \% ; 0,5 \% ; 1,0 \%$ e $1,5 \%$ do PC de concentrado dia ${ }^{-1}$ (Tabela 5), durante 0 período de cinco meses de avaliação (julho a novembro).

Tabela 5. Valores médios de consumo de matéria seca (CMS), proteína bruta (CPB) do suplemento, peso corporal inicial (PCi), ganho médio total (GMT), ganho médio diário (GMD), de cordeiros em terminação a pasto (Urochloa brizantha cv. Marandu) suplementados com diferentes teores de caroço de algodão com grão de milho moído em relação ao peso corporal no período seca na região Sudoeste de mato Grosso.

\begin{tabular}{|c|c|c|c|c|c|c|c|c|c|}
\hline \multirow[t]{2}{*}{ Variáveis } & \multicolumn{4}{|c|}{$\begin{array}{l}\text { Teores de suplementação } \\
\text { concentrada em relação ao peso } \\
\text { corporal }\end{array}$} & \multirow[t]{2}{*}{$\mathrm{R}^{1}$} & \multicolumn{3}{|c|}{ Valor de P } & \multirow[t]{2}{*}{$\% \mathrm{CV}^{5}$} \\
\hline & $0,0 \%$ & $0,5 \%$ & $1,0 \%$ & $1,5 \%$ & & $L^{2}$ & $\mathrm{Q}^{3}$ & $C^{4}$ & \\
\hline CMS do supl. g & 0,00 & 120,00 & 260,00 & 169,00 & - & - & - & - & - \\
\hline CPB do supl. g & 0,00 & 21,00 & 44,00 & 41,00 & - & - & - & - & - \\
\hline PCi kg & 18,29 & 19,57 & 19,50 & 18,86 & NS & 0,669 & 0,268 & 0,348 & 11,81 \\
\hline GMT kg & 11,88 & 12,50 & 13,14 & 13,14 & NS & 0,245 & 0,713 & 0,987 & 17,33 \\
\hline GMD g dia ${ }^{-1}$ & 90,00 & 119,00 & 137,00 & 128,00 & 6 & 0,010 & 0,001 & 0,169 & 11,26 \\
\hline
\end{tabular}

${ }^{1} \mathrm{R}$.: equação de regressão; ${ }^{2} \mathrm{~L}$ : efeito linear; ${ }^{3} \mathrm{Q}$ : efeito quadrático; ${ }^{4} \mathrm{C}$ : efeito cúbico; ${ }^{5} \% \mathrm{CV}$ : coeficiente de variação. Supl: suplemento concentrado. ${ }^{6} Y=0,088921+0,083986 X-0,038143 X^{2}\left(r^{2}=99,01 \%\right)$;

O ponto de máximo para o ganho médio diário (GMD) foi $135,15 \mathrm{~g}$ animal $^{-1}$ dia ${ }^{-1}$ observado para o nível de suplementação concentrada de $1,1 \%$ do peso corporal. Este fato corrobora com informações de Van Soest (1994) e Euclides et al. (1995) de que as forrageiras no período da seca apresentam baixos valores 
GERON, L.J.V. et al. Composição bromatológica e produção de biomassa da Urochloa brizantha cv. Marandu no período da seca na região Sudoeste de Mato Grosso. PUBVET, Londrina, V. 7, N. 17, Ed. 240, Art. 1587, Setembro, 2013.

nutritivos e assim, existe a necessidade de suplementação concentrada, neste período para que os ruminantes possam expressar o seu máximo potencial genético de ganho de peso.

\section{CONCLUSÃO}

A produção de biomassa na matéria natural em quilograma por hectare da Urochloa brizanta cv. Marandu é extremamente comprometida nos meses de agosto e setembro e a produção de biomassa na matéria seca expressa em quilograma por hectare apresenta piores valores no mês de setembro e novembro.

O teor de fibra em detergente neutro da Urochloa brizantha (capim Marandu) produzida na região Sudoeste de Mato Grosso manteve-se constante durante o período de julho a novembro, confirmando que a pastagem do gênero Urochloa ssp., fornece substrato energético para a manutenção da atividade ruminal durante esse período.

O teor de proteína bruta do capim Marandu no período da seca na região Sudoeste de Mato Grosso ficou abaixo das necessidades mínima para um bom funcionamento do rúmen (desenvolvimento das bactérias), sendo assim necessária a suplementação concentrada (protéica) de animais mantidos nestas pastagens não adubadas neste período.

A suplementação concentrada constituída de caroço de algodão com grão de milho moído ( $50 \%$ cada) pode ser realizada até $1,0 \%$ do peso corporal de cordeiros terminados a pasto (capim Marandu), o que melhora o ganho médio diário desses animais no período seco do ano.

\section{AGRADECIMENTOS}

A Fundação de Amparo à Pesquisa do Estado de Mato Grosso (FAPEMAT) por financiado o presente estudo e ter concedido bolsas de iniciação cientifica aos 
GERON, L.J.V. et al. Composição bromatológica e produção de biomassa da Urochloa brizantha cv. Marandu no período da seca na região Sudoeste de Mato Grosso. PUBVET, Londrina, V. 7, N. 17, Ed. 240, Art. 1587, Setembro, 2013.

acadêmicos do Curso de Zootecnia. A Universidade do Estado de Mato Grosso Campus de Pontes e Lacerda - UNEMAT, por ter apoiado e auxiliado no desenvolvimento desta pesquisa cedendo as instalações e equipamentos do Laboratório de Análise de Alimentos e Nutrição Animal (LAANA). Ao senhor e senhora Bragatto por ter fornecido as instalações e animais da fazenda Pau D’Alho para a execução do presente estudo.

\section{REFERÊNCIAS BIBLIOGRÁFICAS}

AIDAR, H.; BARCELLOS, A. O.; COBUCCI, T. Integração lavoura-pecuária pelo consórcio de culturas anuais com forrageira, em área de lavoura, nos sistemas direto e convencional. Ministério da Agricultura e do Abastecimento, 2005. p.7-9.

ANDRADE DE, F. M. E. Produção de forragem e valor alimentício do capim-marandu submetido a regime de lotação continua por bovinos de corte. Piracicaba: 2003. 124p. Dissertação (Mestrado em Agronomia) - Escola Superior de Agricultura Luiz de Queiroz, 2003.

BALSALOBRE, M. A. A.; USSIO, L. G..; MARTHA JUNIOR, G. B. Controle de perdas na produção de silagens de gramíneas tropicais. In: MATTOS, W.R.S.; FARIA, V.P.; DA SILVA, P.C. et al. (Ed.) A produção animal na visão dos brasileiros. Piracicaba:FEALQ, 2001. p.892.

BARCELLOS, A. O.; VILELA, L.; LUPINACCI, A. V. Produção animal a pasto: desafios e oportunidades. In: ENCONTRO NACIONAL DO BOI VERDE: A PECUÁRIA SUSTENTÁVEL, 3., Uberlândia 2001. Anais... Uberlândia: Sindicato Rural de Uberlândia, 2001. p.29.

BARBOSA, A. F.; GRAÇA, D.S.; SOUZA, G.M., Integração lavoura-pecuária: aspectos produtivos na pecuária brasileira, (2008) <http://www.agronomia.com.br/conteudo/artigos/artigos integracao lavoura pecuaria bovina.ht m $(20 / 03 / 2009)$

BUXTON, T. R.; FALES, S. L. Plant enviroment and quality. In: FAHEY Jr., J. C. (Ed.). Forage quality, evaluation and utilization. Madison: American Society. Agronomy, 1994. p. 155-199

CANTARELLA, H. VII - Nitrogênio. In: NOVAIS, R. F.; ALVAREZ V, V. H.; BARROS, N. F. de. et al. Fertilidade do Solo. Editora: SBCS. Viçosa - MG: 2007. P. 375-449.

CANTARUTTI, R. B. Pastagens. IN: RIBEIRO, A. C.; GUIMARAES, P. T. G.; ALVAREZ, Z. V. H (Org.). Recomendações para o uso de corretivos e fertilizantes em Minas Gerais $5^{a}$ aproximação. Minas Gerais: UFV, p. 332 - 338, 1999.

COSTA, C.; LUPATINI, G. C.; MEIRELleS, P. R. L. et al. Produção de forragem cultivares de Brachiaria brizantha: Marandu, Xaraés e Piatã. (2005) <http://prope.unesp.br/xxi cic/27 37007655840.pdf. 
COSTA, C.; FACTORI, M. A.; MEIRELLES, P. R. L. et al. Alternativas para contornar a estacionalidade de produção de forragens. Veterinária e Zootecnia. v.15, n.2, p. 193-203, 2008.

EMPRESA BRASILEIRA DE PESQUISA AGROPECUÁRIA - EMBRAPA. Manual de métodos de análises de solo. 2 ed., Rio de Janeiro, Centro Nacional de Pesquisa de Solos. CNPS, 1997. 212 p.

EMPRESA BRASILEIRA DE PESQUISA AGROPECUÁRIA - EMBRAPA. Sistema Brasileiro de Classificação de Solo. $2^{a}$ ed. Rio de Janeiro: Embrapa: solos, 2006, 306p.

EUCLIDES, V. P. B.; MACEDO, M. C. M.; VALLE, C. B. et al. Animal performance and productivity of new ecotypes of Brachiaria brizantha in Brazil. In: INTERNATIONAL GRASSLAND CONGRESS, 20., 2005, Dublin. Proceedings... Wageningen: Wageningen Academic Publishers, 2005. p.106.

FOOD AND AGRICULTURE ORGANIZATION - FAO. http://www.apps.fao.org/page/ collections?subset=agriculture (20 de abril de 2003).

GARDNER, A. L. 1986. Técnicas de pesquisa em pastagem e aplicabilidade de resultados em sistema de produção. Brasília: IICA/EMBRAPA 3/4 CNPGL. 197p.

GOEDERT, W. J. Desenvolvimento radicular do capim Andropogon gayanus e sua relação com o teor de cálcio no perfil do solo. Revista Brasileira de Ciência do Solo, v.9, p.89-91, 1985.

HODGSON, J. Grazing management: science into practice. London: Longman Scientific and Techinical, 1990. 2003p.

LEPSCH, I. F, et al. Manual para levantamento utilitário do meio físico e classificação das terras no sistema de capacidade de uso, Sociedade Brasileira de Ciência do Solo,Campinas, 1983. 180p.

LUPINACCI, A. V. Reservas orgânicas, índice de área foliar e produção de forragem Brachiaria brizantha cv. Marandu submetida a intensidade de pastejo por bovinos de corte. Piracicaba: Escola Superior de Agricultura Luiz de Queiroz, 2002. 1p. Dissertação (Mestrado em Agronomia) - Escola Superior de Agricultura Luiz de Queiroz, 2002.

MACEDO, M. C. M. Sistema de produção animal em pasto nas savanas tropicais da América: limitações a sustentabilidade (compact disk). In: REUNIÃO LATINOAMERICANA DE PRODUCCIÓN ANIMAL, 16.; CONGRESO URUGUAYO DE PRODUCIÓN ANIMAL, 3.; Montevideo, 2000. Anais.... Argentina: Alfa, 2000.

MACHADO, A. O.; CECATO, U.; MIRA, R. T.; PEREIRA, L. A. F.; MARTINS, E. N.; DAMASCENO, J. C. avaliação da composição química e digestibilidade in vitro da matéria seca de cultivares $\mathrm{e}$ acessos de Panicum maximum Jacq. Sob alturas de corte. Revista Brasileira De Zootecnia, v. 27, n.5, p. 1063, 1998.

MESQUITA, P. Dinâmica do acumulo de forragem em pastos de Brachiaria brizantha cv. Marandu submetidos á lotação contínua e ritmos de crescimento contrastantes. (Dissertação- Mestrado, Piracicaba, 2008) Escola Superior de Agricultura Luiz de Queiroz ESALQ/USP. 2008. 
NABINGER, C. Princípios de exploração intensiva de pastagens. In: SIMPÓSIO SOBRE MANEJO DA PASTAGEM. 13., Piracicaba, 1996. Anais... Piracicaba: FEALQ, 1997b. p.15-95.

PEREIRA, C. G. S.; NUSSIO, L. G.; DA SILVA, S. C. Condições edafo-climáticas para a produção de Cynodon sp. In: SIMPÓSIO SOBRE MANEJO DA PASTAGEM, 15., Piracicaba, 1998. Anais... Piracicaba: FEALQ, 1998. p. 85-113.

PENELLI, M. Características morfogênicas e estruturais do capim braquiarão (Brachiari brizantha \{HOCHITS ex A. Rich.) Stapf. cv Marandu\} sob intensidade de pastejo. Pirassununga: Faculdade de Zootecinia e Engenharia de Alimento da USP, 2003. 23p. Dissertação (Mestrado em Zootecina) Universidade de São Paulo, 2003.

PROHMANN, P. E. F.; BRANCO, A. F.; CECATO, U. et al. Suplementação de Bovinos em Pastagens de Coastcross (Cynodon dactylon L. Pers) no inverno. Revista Brasileira de Zootecnia, v.33, n.4, p.801-810, 2004.

RAMALHO FILHO, A.; BEEK, K. . Sistema de avaliação da aptidão agrícola das terras. 3.ed . rev. Rio de Janeiro: Embrapa-cnps, 1995. 65p.

RAMALHO FILHO, A.; PEREIRA, L. C. Aptidão agrícola das terras do Brasil: potencial de terras e análise dos principais métodos de avaliação Rio de Janeiro : Embrapa Solos, 1999. $36 \mathrm{P}$.

SILVA, S. C. Condições edafoclimáticas para a produção de Panicum sp. In: SIMPÓSIO SOBRE MANEJO DE PASTAGENS, 12., Piracicaba, 1995. Anais... Piracicaba: FEALQ, 1995.p.129.

SILVA, S. C.; PEREIRA, C. G. S. Princípios de ecologia aplicados ao manejo de pastagem. In: SIMPÓSIO SOBRE ECOSSISTEMA DE PASTAGENS, 3., Jaboticabal, 1997. Anais... Jaboticabal: FUNEP, 1997b. p1.

SILVA, D. J.; QUEIROZ. A. C. Análise de alimentos (Métodos químicos e biológicos). $2^{\mathrm{a}}$ ed., Viçosa, MG: UFV. 2002, 178p.

SHUMANN, A. M.; GERON, L. J. V.; MEXIA, A. A.; ALVES JÚNIOR, R. T.; GARCIAL, J.; GARCIA, R. R. F. Produção de matéria natural e matéria seca da Brachiaria brizantha no período da seca na região de tensão ecológica do Vale do Guaporé. In: V CONGRESSO INTERNO DE INICIAÇÃO CIENTÍFICA - UNEMAT. Anais... 5, 2009. Cáceres: UNEMAT, 2009 Cd-row.

SOUSA, D. M. G.; LOBATO, E. Correção da acidez do solo. In: CERRADO: CORREÇÃO DO SOLO E ADUBAÇÃO. Planaltina: Embrapa Cerrados. p. 81 - 96. 2004.

TAIZ, L.; ZAIGER, E. Fisiologia vegetal. 3.ed. Porto Alegre. Artmed, 2004. 719p.

TONATO, F. Determinação de parâmetros produtivos e qualitativos de Cynodon spp. em função de variáveis climáticas. Piracicaba, 2003. 82p. Dissertação (Mestrado) - Escola Superior de Agricultura "Luiz de Queiroz", Universidade de São Paulo.

UNIVERSIDADE FEDERAL DE VIÇOSA - UFV. Sistema de análises estatísticas e genéticas SAEG. Viçosa: UFV. 150p. 1997. (Manual do usuário). 
VAN SOEST, P. J. Nutritinal ecology of the ruminant- ruminant metabolism, Nutitional strategies, the chemistry of forage and plant fibers. O\&B Boocks, Inc. Corvallis, Oregon, USA. 1 ed. 373p. 1982.

VAN SOEST, P. J.; ROBERTSON, J. B.; LEWIS, B. A. Methods for dietary fiber neutral detergent fiber, and nostarch polysaccharides in relation to animal nutrition. Journal of Dairy Science, v.74, n.12, p.3583-3597, 1991.

VAN SOEST, P. J. Nutritional ecology of the ruminant. 2. ed. New York: Cornell University, 1994.

WERNER, J. C. Importância da interação solo-planta-animal na nutrição de ruminantes. In: CURSO DE ATUALIZAÇÃO EM NUTRIÇÃO ANIMAL, v.1, 1993. Brasília: MAARA/SDR/SENA. Anais.. Brasília, 1993. p.11-20.

WERNER, J. C. Adubação de pastagens de Brachiaria spp. In: SIMPÓSIO SOBRE MANEJO DA PASTAGEM, 11., 1994, Piracicaba. Anais... Piracicaba: FEALQ, 1994. p.202-209.

WILM, H. G.; COSTELO, O. F.; KLIPPLE, G. E. Estimating forage yield by the double sampling method. Jornal American of Agronomic, v.36, n.1, p. 194-203, 1944. 